\title{
BURNING MOUTH SYNDROME AND SQUAMOUS CELL CARCINOMA: COINCIDENCE OR A NEW DISEASE ASSOCIATION
}

\author{
Todor Yordanov ${ }^{1}$, Neli Koleva ${ }^{2}$, Jenya Dimitrova ${ }^{3}$, Elisaveta Popchristova ${ }^{2}$, \\ Irina Yungareva ${ }^{1}$, Tsveta Kalinova ${ }^{3}$, Sonya Marina ${ }^{1}$ \\ ${ }^{1}$ Department of Skin and Venereal Diseases, \\ Medical Institute of the Ministry of Internal Affairs \\ ${ }^{2}$ Department of Clinical Pathology, Medical Institute of the Ministry of Internal Affairs \\ ${ }^{3}$ Department of Infectious Diseases, Parasitology and Dermatovenereology, \\ Faculty of Medicine, Medical University of Varna
}

\begin{abstract}
Burning mouth syndrome (BMS) is described as a burning feeling or sensation in the mouth in the absence of specific oral mucosa lesions. Patients with BMS often complain of paraesthesia (tingling sensation in the mouth), xerostomia (dry mouth sensation), changes in sense of taste and smell. In the past two decades, significant research of this condition has been conducted. Psychological, systemic and local factors probably play a role in the pathogenesis of BMS. We present a case of an 82-year-old female with burning sensation in the mouth and coexisting growing lesion on her lower lip.
\end{abstract}

Keywords: burning mouth syndrome, stomatodynia, pain management

The International Association for the Study of Pain defines burning mouth syndrome (BMS) as "a distinctive nosological entity characterized by unremitting oral burning or similar pain in the absence of detectable mucosal changes" (1). The International Headache Society defines it as "an intra-oral burning sensation for which no medical or dental cause can be found". There are many synonyms like: stomatodynia, sto-

\footnotetext{
Address for correspondence:

Jenya Dimitrova

Faculty of Medicine

Medical University of Varna

55 Marin Drinov St

9002 Varna

e-mail:dimitrova_derm@abv.bg
}

Received: April 9, 2020

Accepted: June 18, 2020 matopyrosis, glossopyrosis, glossodynia, sore mouth, sore tongue or oral dysesthesia (2).The prevalence of burning mouth syndrome ranges from $0.7 \%$ to $4.6 \%$ and affects mostly 55 - to 60 -year-olds. The woman to man ratio varies from 3:1 to $16: 1$. Individuals with BMS may also experience sensation of bitter or metallic taste due to disturbance of sensory modalities of small diameter afferent fibers. Dry mouth is another common complaint. Studies report that patients with BMS may have associated conditions like: headaches, dizziness, irritable bowel syndrome, musculoskeletal, dermatological or psychiatric disorders. There is still no universal consensus on the diagnosis, etiology, and treatment of BMS.

We present a case of 82-year-old woman with burning sensation in the mouth for 7 months and a growing lesion on the lower lip who was admitted to the Department of Dermatology and Venereology of the Medical Institute of Ministry of Internal Affairs. The patient had also history of swallowing difficul- 
ty and increasing painful sensation throughout the day. She reported depressive episodes due to her oral complaints. The only abnormality detected by laboratory tests was low level of vitamin B12 - 104 pg/mL. After a consultation with a hematologist and a psychiatrist, treatment with antidepressant medication and vitamin B12 was initiated. No evidence for hypersensitivity to dental materials was found.

The physical examination found redness of the tongue with enlarged vallate papillae and white tongue coating. The buccal and palatal mucosa was intact. On the lower lip there was a solitary, round papule with an infiltrated border and central hemorrhagic crust and a diameter of $11 \mathrm{~mm}$ (Fig. 1). In the differential diagnosis squamous cell carcinoma, basal cell carcinoma and viral wart were taken into consideration. The histopathological examination showed nests of squamous epithelial cells arising from the epidermis and extending into the dermis. The malignant cells were big with eosinophilic cytoplasm and large, often vesicular, nuclei. Variable keratinisation was present (Fig. 2).

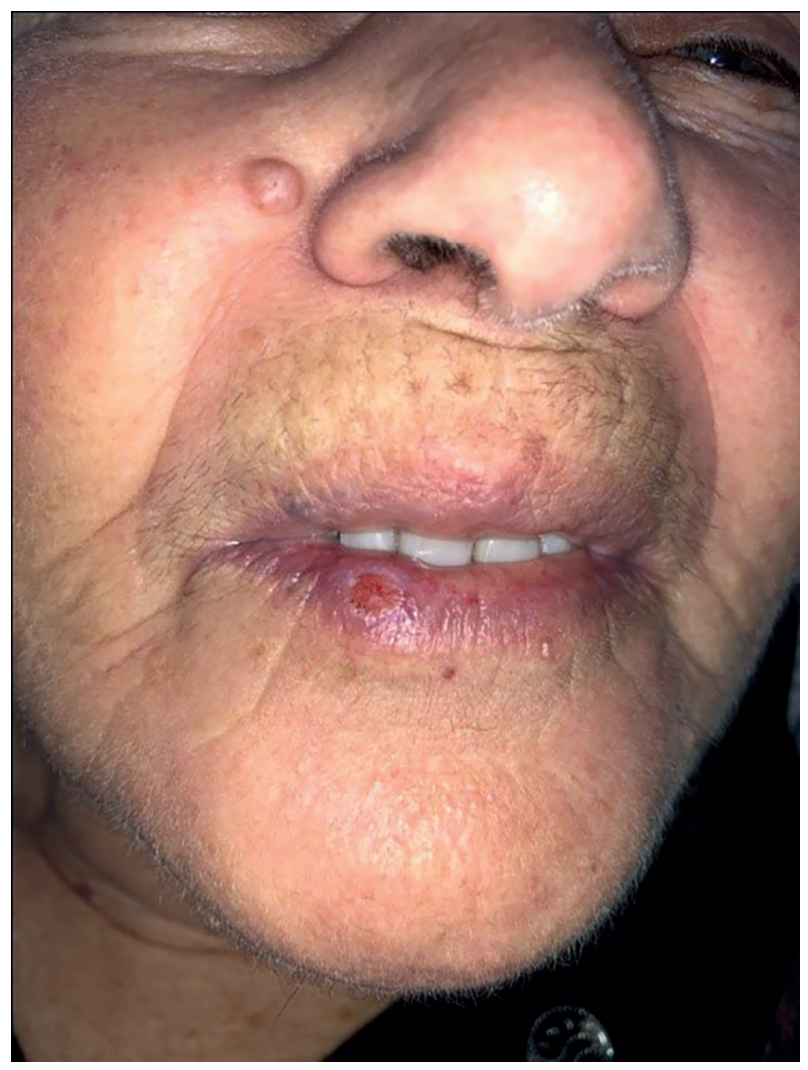

Fig. 1. Lower lip lesion

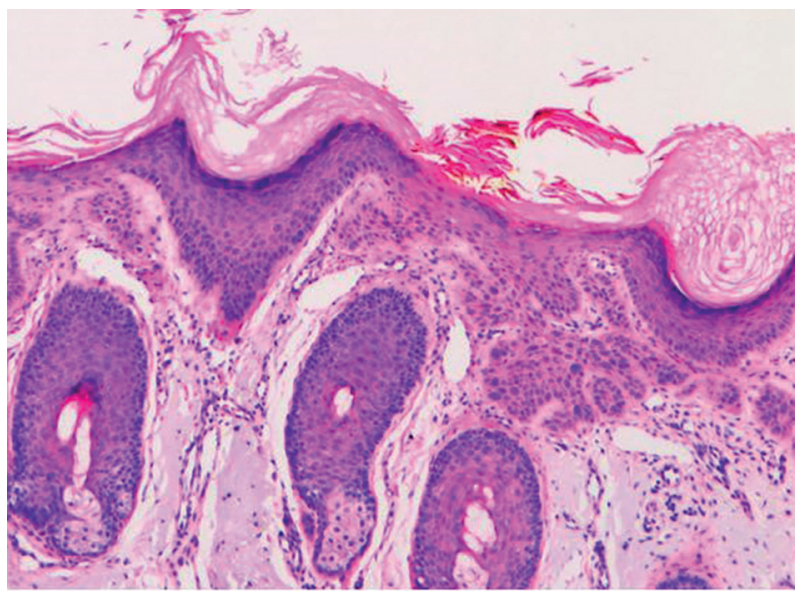

Fig. 2. Histopathological findings

Histopathological examination confirmed the diagnosis squamous cell carcinoma, so the patient was consulted with an oral and maxillofacial surgeon and planned for surgical treatment.

BMS is a chronic and intractable pain syndrome with multifactorial origin, often idiopathic. The etiological factors can be divided into three groups:

1. Local: poorly fitting tooth prostheses, dental treatment, allergic contact stomatitis, infections, xerostomia.

2. Systemic: endocrine diseases, deficient states, medications, esophageal reflux.

3. Psychological: anxiety, depression, obsessive compulsive disorder (OCD), cancerophobia.

The main clinical features of BMS are: unilateral or bilateral burning sensation; pain with increasing intensity at the end of the day; decreased pain on eating; decreased pain during sleep; absence of objective clinical findings; dry mouth; paraesthesia.

One of the commonly used classification divides BMS into 3 types:

1. Type 1: Characterized by progressive pain throughout the day. Affects approximately $35 \%$ of patients. This type may be associated with systemic diseases, such as nutritional deficiencies.

2. Type 2: Symptoms are constant throughout the day and patients find it difficult to fall asleep. About 55\% of cases are of this type. It is usually associated with psychological disorders. 
3. Type 3: Symptoms are intermittent, with atypical location and pain. $10 \%$ of patients have this BMS type. It is usually associated with allergies.

Another pragmatic approach is suggested by A. Scala et al. (3). BMS is classified as: primary (idiopathic) and secondary BMS (resulting from local or systemic factors).

Usually the resolution of the condition is spontaneous, but in one third of cases persists for a long period of time. The appropriate diagnostic approach is very important for the adequate treatment. Taking a comprehensive history on the onset, localization, intensity and duration of the complaints is crucial. Physical examination is performed for oral or general clinical signs. In most of the cases salivary flow rates should also be estimated. Consultation with neurologist should be done if there are corresponding symptoms.

Treatment of BMS is still disappointing (4). For adequate therapeutic approach it should be determined whether the patient is suffering from primary or secondary BMS. Medications of choice are antidepressants, antiepileptic drugs, analgesics, alpha lipoic acid as a neuroprotector, topical steroids, hormone replacement therapy. As the pathogenesis of BMS remains unclear, the treatment is usually unsatisfactory (5). An interdisciplinary and systematic approach is required for better patient management.

In the presented case BMS coexisted with squamous cell carcinoma. We suggest that between the two conditions may be interconnection. The early detection and definitive treatment of the neoplasm is important for prevention of perineural and perivascular metastases.

\section{REFERENCES}

1. Grushka M. Clinical features of burning mouth syndrome. Oral Surg Oral Med Oral Pathol. 1987;63(1):30-6. doi: 10.1016/0030-4220(87)90336-7.

2. Headache Classifications Subcommittee of the International Headache Society. The international classification of headache disorders. Cephalalgia. 2004;24(11):9-160.

3. Scala A, Checchi L, Montevecchi M, Marini I, Giamberardino MA. Update on burning mouth syndrome: overview and patient management. Crit Rev Oral Biol Med. 2003; 14(4):275-91. doi: 10.1177/154411130301400405.

4. Barker KE, Savage NW. Burning mouth syndrome: an update on recent finding. Aust Dent J. 2005;50(4):220-3. doi: 10.1111/j.1834-7819.2005. tb00363.x.

5. Patton LL, Siegel MA, Benoliel R, De Laat A. Management of burning mouth syndrome: systematic review and management recommendations. Oral Surg Oral Med Oral Pathol Oral Radiol Endod. 2007;103:1-13. doi: 10.1016/j. tripleo.2006.11.009. 